\title{
PENERAPAN DIGITAL MARKETING SEBAGAI STRATEGI PEMASARAN UMKM
}

\author{
Rahmatul Jannatin $N^{1}$, M. Wahyu Wardhana2, ' Rudi Haryanto ${ }^{3}$, Agus Pebriyanto ${ }^{4}$ \\ Politeknik Negeri Banjarmasin ${ }^{1,2,3,4}$ \\ jannatinnaimah@gmail.com ${ }^{1}$ why_wrd@yahoo.com ${ }^{2}$, roedy96@gmail.com ${ }^{3}$, \\ agoesyoriko@yahoo.com ${ }^{4}$
}

\begin{abstract}
Community Service Partners in this activity are Micro, Small and Medium Enterprises (MSMEs) in the business of producing and selling teak furnitures in Banjarmasin. This MSME has been in Banjarmasin City for more than 30 years. However, the marketing system that used is still very minimal and conventional. For this reason, MSMEs need to be given training on the importance of using digital marketing so that the marketing system can be better to achieve the desired targets and can support better sales activities. In addition, MSMEs also provide assistance in creating business accounts in digital media such as Google Business and Instagram, and how to manage this digital media optimally Output from this ativity is a Google business and Instagram Business account, scientific article published in national journals, and activity reports. The method used is by provide training to create accounts in digital media for the MSME and how to manage it optimally. The results showed that digital marketing strategy assistance by Community Service Partners can be followed up with periodic guidance that can be done effectively and optimally in supporting MSME marketing activities to increase sales of MSME businesses.
\end{abstract}

Keywords: digital marketing, UMKM, marketing strategy

\begin{abstract}
ABSTRAK
Mitra Pengabdian Masyarakat pada kegiatan ini adalah Usaha Mikro Kecil dan Menengah (UMKM) yang bergerak dalam bidang usaha produksi dan jual beli furniture jati di Kota Banjarmasin. UMKM yang menjadi Mitra Pengabdian ini sudah sangat lama berdiri di Kota Banjarmasin, yaitu hampir lebih dari 30 tahun. Akan tetapi dalam kegiatan pemasarannya masih sangat minim dan konvensional. Untuk itu UMKM ini perlu diberikan pelatihan tentang pentingnya pemanfaatan digital marketing agar sistem pemasarannya menjadi lebih baik sehingga dapat memperluas cakupan target usahanya serta dapat menunjang kegiatan penjualan yang lebih baik lagi. Selain itu, UMKM juga diberikan bantuan dalam membuat akun bisnis di media digital yaitu Google Bisnis dan Instagram, beserta cara mengelola media digital tersebut secara optimal. Luaran yang dihasilkan dari pengabdian ini adalah akun Google bisnis dan Instagram, artikel ilmiah yang diterbitkan dalam jurnal nasional, serta laporan kegiatan. Metode yang digunakan adalah dengan memberikan pelatihan berupa ceramah dan pemberian tutorial membuat akun di media digital beserta cara mengelola media digital tersebut. Dari hasil yang diperoleh dalam kegiatan ini, disarankan sebaiknya penggunaan strategi digital marketing dapat ditindaklanjuti dengan pembimbingan secara berkala sehingga bisa efektif dan optimal dalam menunjang kegiatan pemasaran dan meningkatkan penjualan usaha UMKM.
\end{abstract}

Kata Kunci: digital marketing, UMKM, strategi pemasaran 


\section{PENDAHULUAN}

Perkembangan teknologi informasi telah mengubah lingkup dunia pemasaran dalam beberapa tahun terakhir ini. Metode komunikasi pemasaran yang sebelumnya bersifat tradisional dan konvensional, kini telah terintegrasi dalam dunia digital (Ascharisa, 2018). Kegiatan pemasaran yang memanfaatkan kecanggihan teknologi digital seringkali disebut dengan digital marketing. Digital marketing terdiri dari pemasaran interaktif dan terpadu yang memudahkan interaksi antara produsen, perantara pasar dan calon konsumen (Purwana et al, 2017).

Di era sekarang ini, para pelaku UMKM hendaknya bisa memanfaatkan media digital sebagai salah satu upaya pemasaran produknya sehingga konsumen lebih mengenal produk yang dihasilkan oleh UMKM tersebut. UMKM yang memiliki akses online, terlibat di media sosial, dan mengembangkan kemampuan ecommerce-nya, biasanya akan menikmati keuntungan bisnis yang signifikan baik dari segi pendapatan, kesempatan kerja, inovasi, dan daya saing Akan tetapi, masih banyak UMKM yang belum menerapkan teknologi informasi khususnya menggunakan media digital dan belum mengerti seberapa besar manfaat dan peranan penggunaan media digital tersebut. (Wardhana, 2018)

Salah satu media digital marketing yang sering digunakan adalah Googe Bisnis. Google Bisnis merupakan aplikasi gratis yang dapat digunakan untuk membantu agar bisnis para pelaku UMKM dapat ditemukan di berbagai produk Google, seperti di Maps dan penelusuran. Jika pelaku UMKM menjalankan bisnis yang melayani pelanggan dilokasi tertentu, atau melayani pelanggan di area layanan yang ditentukan, GoogleBisnis dapat membantu orang lain menemukan bisnis UMKM tersebut. (Ridwan et al, 2019)

Media lain yang juga seringkali digunakan dalam digital marketing adalah media sosial, salah satunya Instagram. Instagram memiliki fitur Akun Bisnis yang memudahkan pelaku bisnis untuk membuat profil bisnis di Instagram dan mengoptimalkan kegiatan bisnis dengan memanfaatkan media sosial tersebut. Dengan fitur ini, perusahaan dengan berbagai ukuran dapat memperkenalkan profil bisnisnya, memperoleh wawasan tentang pengikut dan kiriman, serta mempromosikan kiriman untuk mendorong tujuan bisnis. (Rachmawati, 2018)

Adapun Mitra dalam pelaksanaan pengabdian ini adalah Meubel Rapi Sari yang bergerak dalam bidang usaha produksi dan jual beli barang furniture yang sudah sangat lama berdiri di Kota Banjarmasin, yaitu lebih dari 30 tahun. Dalam kegiatan jual beli furniture di Banjarmasin, Rapi Sari Meubel termasuk yang paling pertama membuka usaha di bidang tersebut serta yang paling lama bertahan hingga saat ini. Akan tetapi dalam kegiatan pemasarannya masih sangat minim dan cenderung masih tradisional. Untuk itu perlu diberikan pelatihan tentang pentingnya pemanfaatan digital marketing agar sistem pemasarannya menjadi lebih baik sehingga dapat memperluas cakupan target usahanya serta dapat menunjang kegiatan penjualan yang lebih baik lagi. Selain itu mitra juga diberikan bantan dalam membuat akun di media digital (Google bisnis dan Instagram) 
beserta cara mengelola media digital tersebut secara optimal untuk kebutuhan promosi usaha UMKM.

\section{METODE KEGIATAN}

\section{Lokasi Pelaksanaan Pengabdian}

Kegiatan Pengabdian kepada masyarakat dengan judul "Penerapan Digital Marketing Sebagai Strategi Pemasaran UMKM" dilaksanakan di Showroom Meubel Rapi Sari Banjarmasin, dengan alamat Jalan Pangeran Antasari No 113A RT 01 Banjarmasin.

\section{Peserta}

Kegiatan ini diikuti oleh perwakilan pimpinan dan staf yang ditunjuk serta beberapa tenaga penjualan Rapi Sari Meubel Banjarmasin dan didukung oleh mahasiswa semester 6 DIII Administrasi Bisnis Politeknik Negeri Banjarmasin

\section{Metode Pelaksanaan}

Pelaksanan kegiatan diberikan dalam bentuk pelatihan yang dibagi menjadi dua metode:

1. Menggunakan metode ceramah tentang pentingnya peranan digital marketing bagi perkembangan bisnis UMKM, terutama dalam hal meningkatkan kegiatan promosi. Ceramah juga disertai dengan beberapa contoh UMKM yang telah sukses menggunakan media digital untuk kegiatan promosi. Sehingga diharapkan pelaku UMKM sadar akan pentingnya pemanfaatan digital marketing di era sekarang ini.

2. Memberikan praktek langsung disertai tutorial pembuatan akun di media digital. Adapun media digital yang digunakan adalah Google Bisnis dan akun bisnis di media sosial Instagram. Pemberian tutorial hendaknya juga disertai dengan pengetahuan bagi UMKM tentang bagaimana mengoptimalkan semua fitur yang ada di kedua media digital tersebut.

Peralatan dan bahan yang digunakan adalah sebagai berikut:

1. Laptop, LCD, dan layar proyektor yang berguna untuk menampilkan materi pelatihan dalam bentuk ceramah maupun praktek tutorial.

2. Gadget berupa Handphone beserta paket data ataupun jaringan internet. Gadget ini berguna untuk mengakses media digital yang akan dibuat akunnya untuk pelaku UMKM tersebut.

\section{Langkah Kerja}

Adapun langkah pelaksanaan kegiatan antara lain:

1. Koordinasi dengan mitra, terkait dengan penyusunan jadwal kegiatan, lokasi kegiatan, serta peserta kegiatan. Dalam koordinasi awal ini diharapkan dapat dipilih lokasi, hari, dan jam yang tepat sehingga pemberian materi pelatihan bisa maksimal dan tepat sasaran. Selain itu pihak UMKM akan menunjuk siapa saja karyawan yang dianggap tepat untuk mengikuti pelatihan. Sekurang-kurangnya peserta yang hadir diharapkan ada beberapa dari tenaga 
penjualan, perwakilan dari staf pemasaran, serta perwakilan dari pemilik UMKM itu sendiri.

2. Persiapan penyuluhan dan pelatihan. Dalam hal ini yang disiapkan berupa materi yang akan ditampilkan dalam sesi ceramah, persiapan pembicara, materi print out yang akan dibagikan kepada peserta, cek dan penataan lokasi kegiatan, serta persiapan peralatan dan persiapan pendukung seperti daftar hadir peserta, konsumsi, back drop dan lain-lain.

3. Pelaksanaan pelatihan sesi pertama yaitu berupa ceramah tentang pentingya menggunakan digital marketing akan diberikan oleh salah satu dari anggota tim pengusul. Lama sesi ceramah kurang lebih 30 menit disusul dengan sesi tanya jawab.

4. Kemudian pelaksanaan pelatihan sesi ke dua yaitu pemberian praktek serta tutorial membuat akun di Google bisnis dan Instagram beserta cara untuk mengelola akun tersebut dengan optimal. Lama sesi kurang lebih 60 menit. Materi praktek akan disampaikan oleh satu satu dari anggota pengusul.

5. Penulisan laporan kegiatan.

\section{HASIL DAN PEMBAHASAN}

\section{Hasil yang Dicapai}

Hasil yang di capai melalui kegiatan Pengabdian Masyarakat dengan judul Penerapan Digital marketing Sebagai Strategi Pemasaran UMKM yang dilakukan oleh dosen Program Studi Administrasi Bisnis ini dituangkan dalam bentuk laporan hasil kegiatan pada setiap tahap pelaksanaan sebagai berikut:

1. Koordinasi dengan pihak UMKM pada hari Senin, tanggal 19 Agustus 2019 selaku Mitra Pengabdian untuk menentukan lokasi, hari, dan jam yang tepat sehingga pemberian materi pelatihan bisa maksimal dan tepat sasaran. Adapun tanggal yang disepakati adalah hari Rabu, 04 September 2019 pukul 10.00 - 12.00 WITA. Hari dan jam ini disepakati sesuai dengan kesediaan UMKM selaku Mitra Pengabdian. Selain itu dari hasil koordinasi ditetapkan bahwa sekurang-kurangnya peserta yang hadir diwakili oleh 4 orang tenaga penjualan, dan 1 orang tenaga staff serta 1 orang perwakilan dari pemilik UMKM itu sendiri.

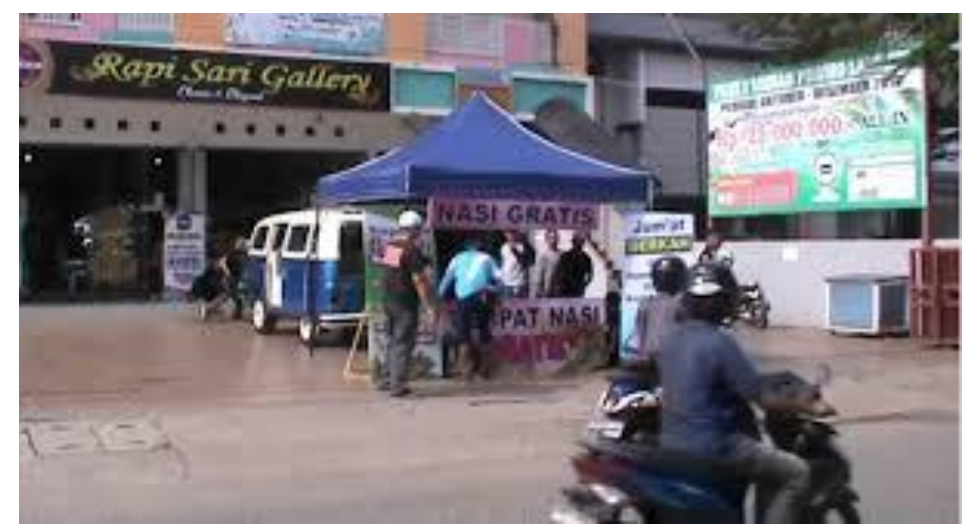

Gambar 1. Lokasi Mitra Pengabdian 


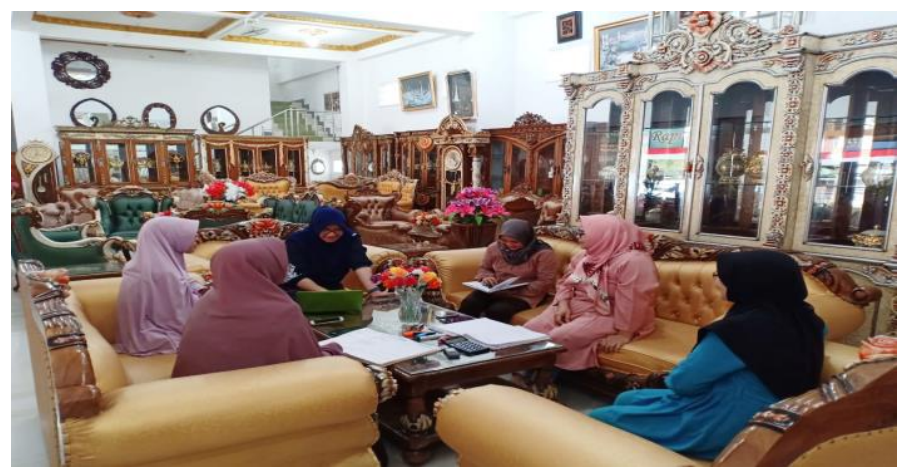

Gambar 2. Koordinasi Awal dengan Mitra UMKM

2. Persiapan penyuluhan dan pelatihan dari tanggal 20-31 Agustus 2019. Dalam hal ini yang disiapkan berupa materi yang akan ditampilkan dalam sesi ceramah, persiapan pembicara, materi print out yang akan dibagikan kepada peserta, cek dan penataan lokasi kegiatan, serta persiapan peralatan dan persiapan pendukung seperti daftar hadir peserta, konsumsi, back drop dan lain-lain.

3. Pelaksanaan pelatihan sesi pertama pada tanggal 04 September 2019 pukul 10.00 WITA yaitu berupa pemberian materi tentang pentingnya menggunakan digital marketing yang diberikan oleh salah satu dari anggota tim pengusul. Lama sesi pertama kurang lebih 30 menit disusul dengan sesi tanya jawab. Peserta pelatihan sesi pertama dihadiri oleh 4 orang tenaga penjualan, 1 orang tenaga staff, serta 1 orang perwakilan dari pemilik usaha UMKM.

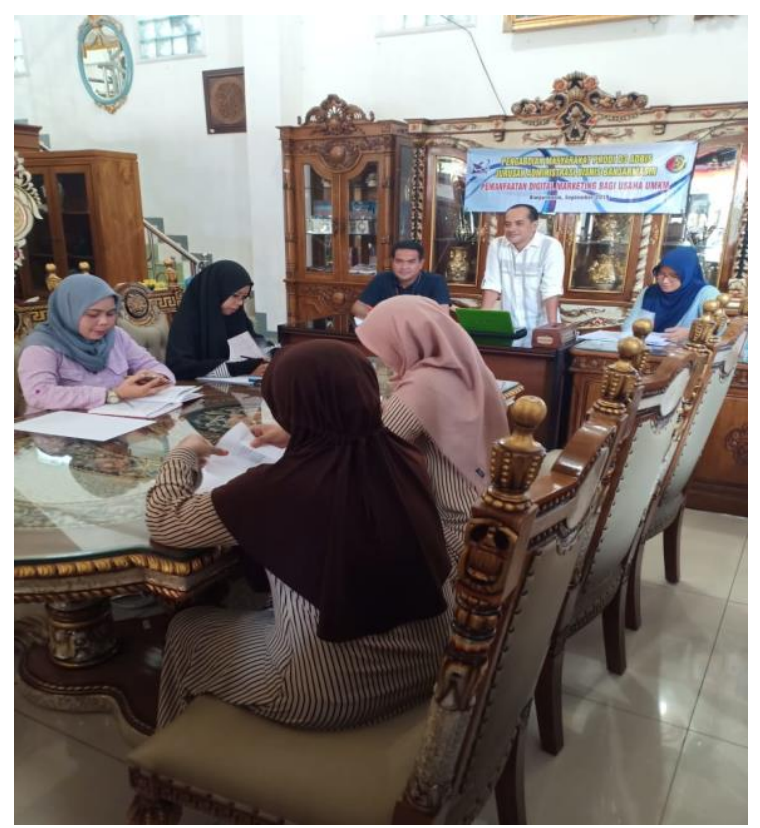

Gambar 3. Pemberian Materi Pada Sesi Pertama 


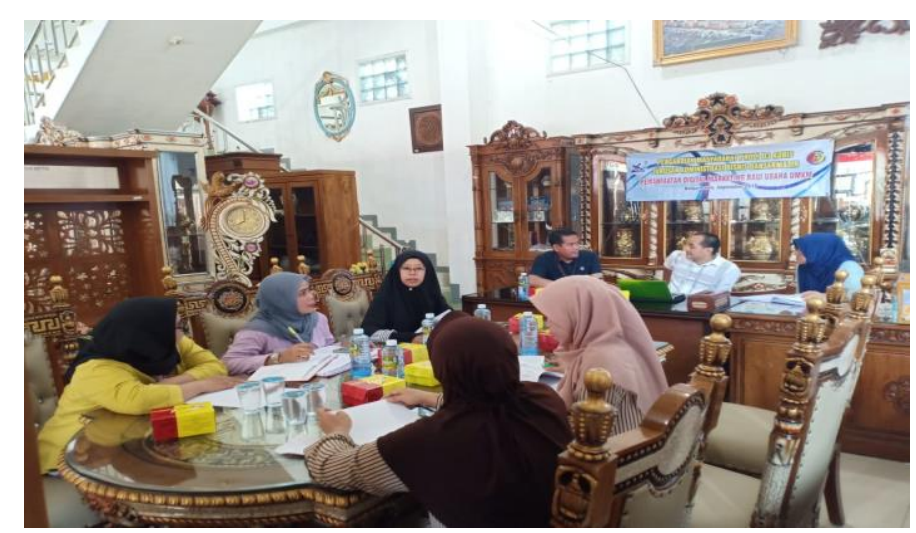

Gambar 4. Sesi Diskusi Pada Sesi Pertama

4. Kemudian dilanjutkan dengan pelaksanaan pelatihan sesi ke dua, pukul 11.00 WITA masih di hari yang sama, yaitu pemberian praktek serta tutorial membuat akun di Google bisnis dan Instagram beserta cara untuk mengelola akun tersebut dengan optimal. Lama sesi kurang lebih 60 menit. Materi praktek disampaikan oleh satu satu dari anggota pengusul. Peserta pelatihan sesi ke dua dihadiri oleh 4 orang tenaga penjualan, 1 orang tenaga staff, serta 1 orang perwakilan dari pemilik usaha UMKM.

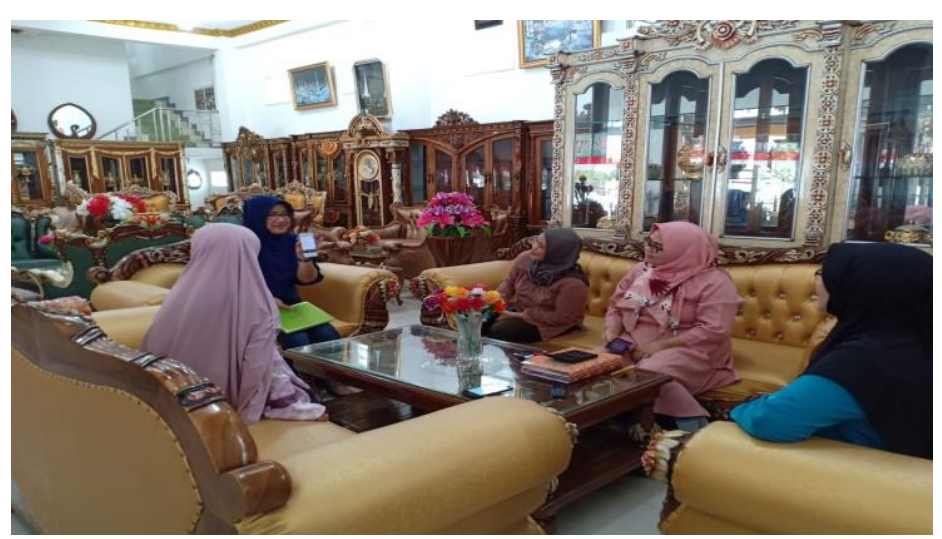

Gambar 5. Tutorial Pembuatan dan Pengelolaan Akun Google Bisnis

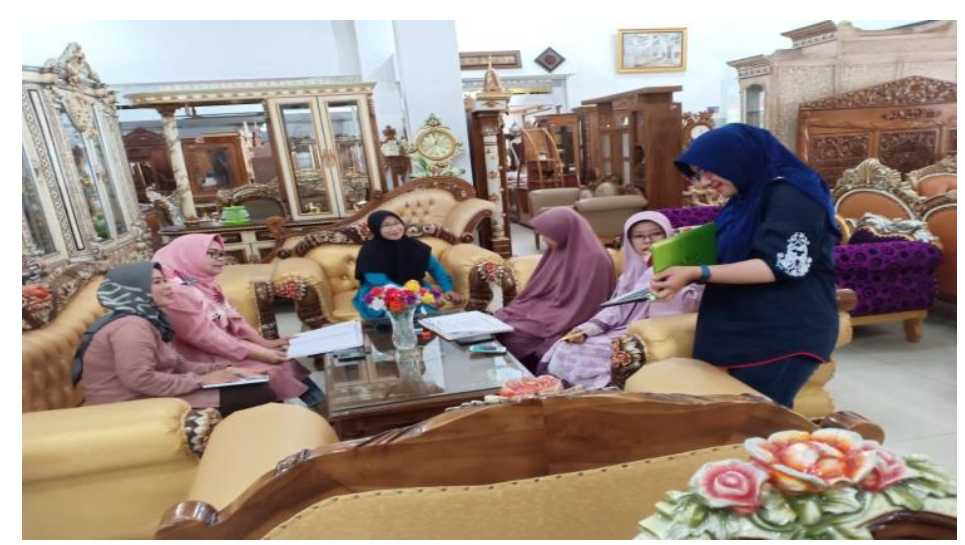

Gambar 6. Tutorial Pembuatan dan Pengelolaan Akun Instagram Bisnis 
5. Terakhir kegiatan pengabdian ditutup dengan sesi foto bersama dan ucapan terima kasih dari pihak tim pelaksana kegiatan pengabdian kepada Mitra Pengabdian dengan harapan agar bantuan digital marketing yang dibeikanbisa bermanfaat bagi kemajuan usaha UMKM ke depannya. Kegiatan berakhir pada pukul 12.30 WITA.

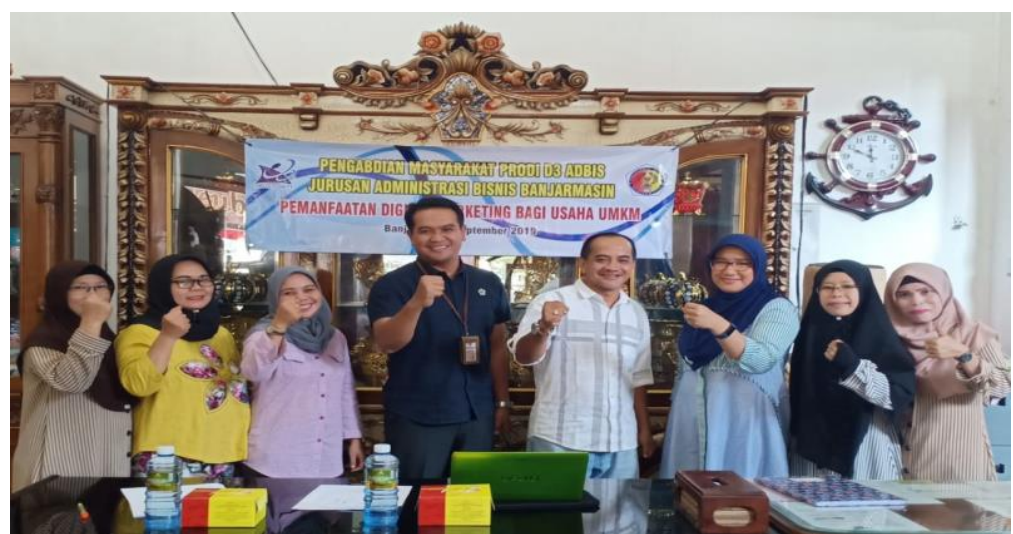

Gambar 7. Sesi Foto Bersama Tim Pelaksana Beserta Peserta Kegiatan

\section{Solusi dan Luaran yang Dicapai}

Adapun solusi dari pengabdian kepada masyarakat "Penerapan Digital marketing Sebagai Strategi Pemasaran UMKM" ini adalah sebagai berikut:

1. Pemberian pelatihan mengenai pemanfaatan digital marketing sebagai sarana pemasaran produk usaha. Selain itu disisipkan juga masukan berupa contoh UMKM yang telah memanfaatkan digital marketing terkait. Dengan adanya pelatihan ini diharapkan dapat memberikan solusi bagi permasalahan UMKM yaitu kurangnya pemahaman, kemampuan dan pengetahuan UMKM mengenai pentingnya digital marketing dalam rangka memaksimalkan kegiatan promosi.

2. Pemberian tutorial pembuatan akun di media digital yang berpotensi untuk memperluas jangkauan pemasaran UMKM. Media digital yang digunakan di sini adalah Google Bisnis dan Media Sosial yaitu Instagram. Pelaku UMKM diberikan tutorial dan praktek membuat akun di ke dua media digital tersebut beserta cara mengoptimalkan ke dua media digital tersebut sebagai sarana promosi untuk jangkauan pemasaran yang lebih luas sehingga mampu mendorong penjualan produk yang lebih baik. Berikut ini beberapa hasil dari akun Google bisnis dan Instagram bisnis yang berhasil dibuat oleh Tim Pelaksana Kegiatan Pengabdian. 


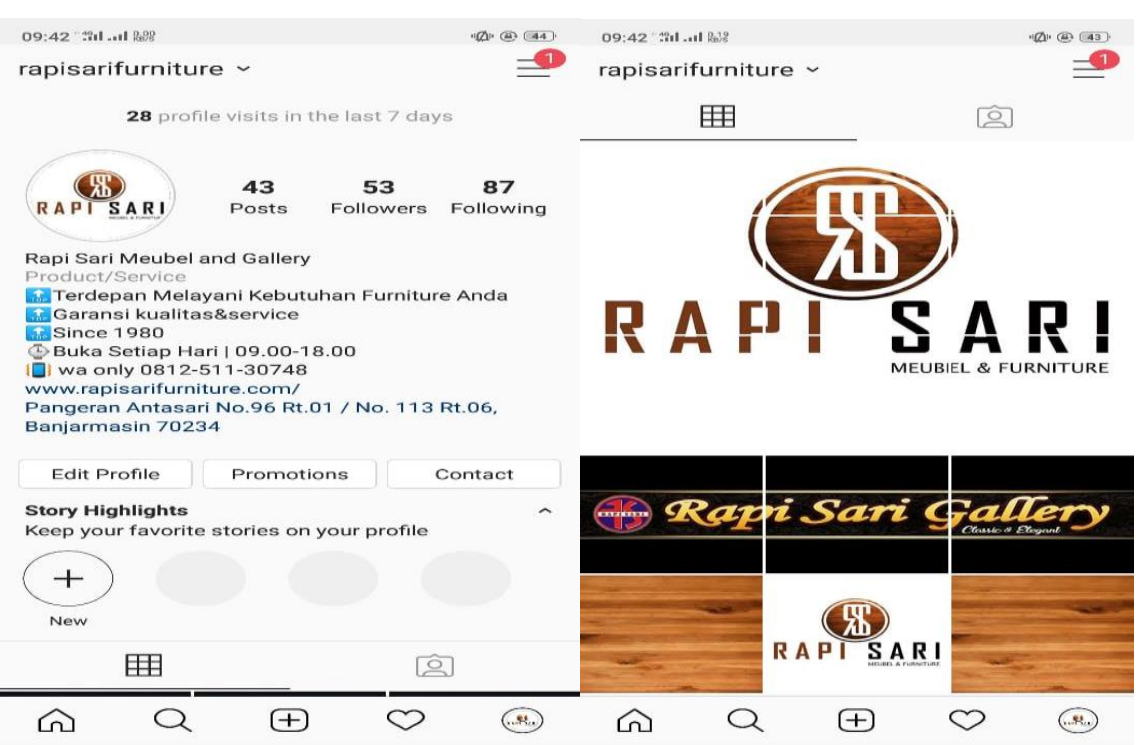

Gambar 8. Screenshot Feeds Akun Instagram Bisnis Mitra UMKM

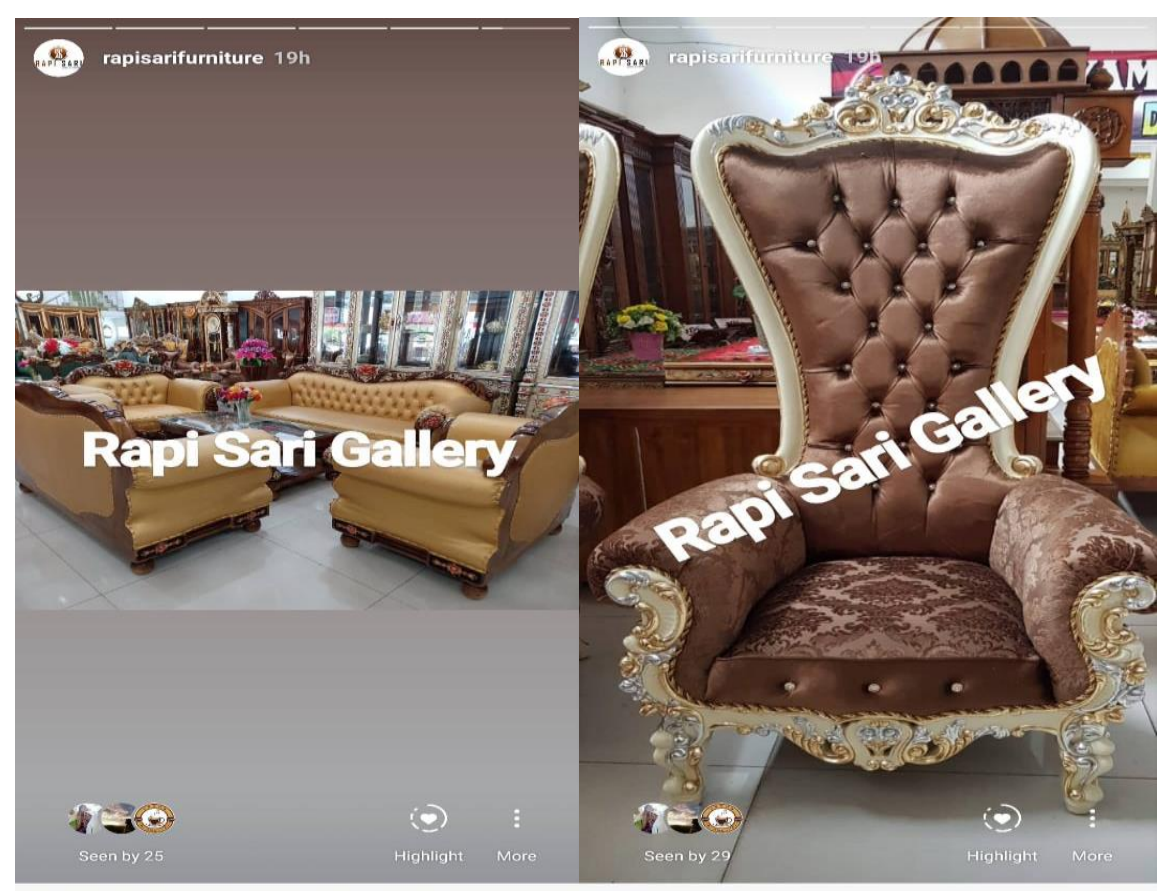

Gambar 9. Screenshot IG Stories Akun Instagram Bisnis Mitra UMKM 


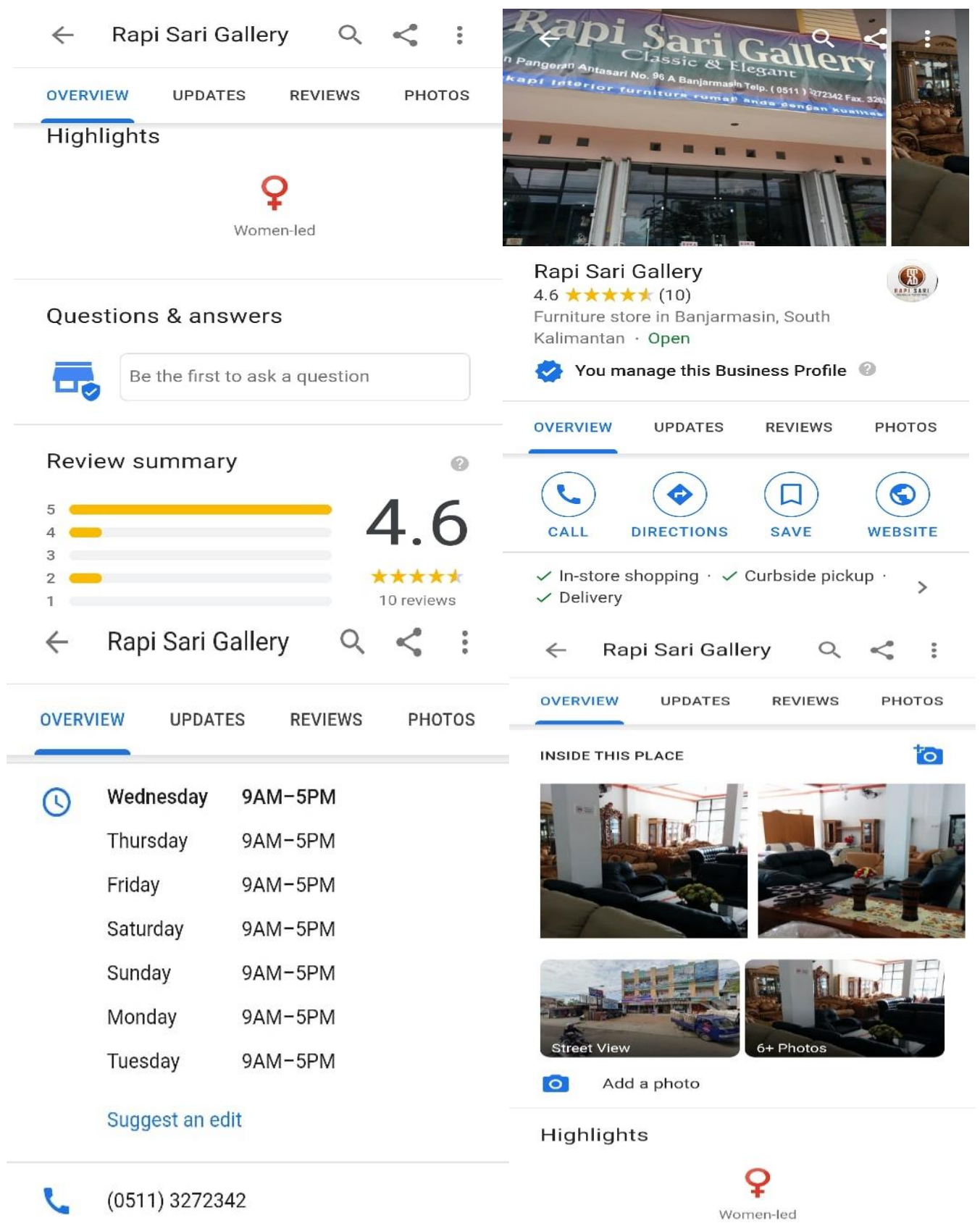




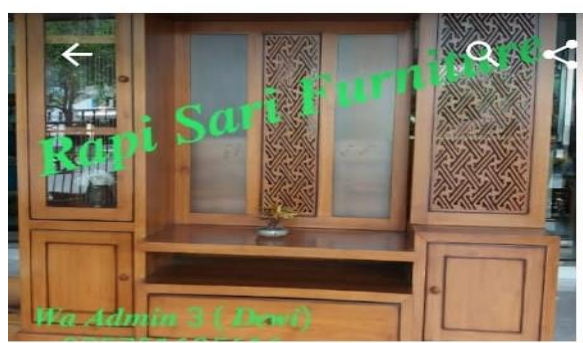

Rapi Sari Meubel $4.6 * \star * k * *(8)$

Furniture store in Banjarmasin, South Kalimantan - Open

2. You manage this Business Profile

UPERVIEW

$\leftarrow$ Rapi Sari Meubel $\quad<<$ :
Rapi Sari Meubel $4.6 * * * * x$ (8)

Toko mebel di Banjarmasin.

Kalimantan Selatan . Open

Anda mengelola Profil Bisnis ini$$
\text { RINGKASAN YANG ULASAN FOTO TENTANG }
$$
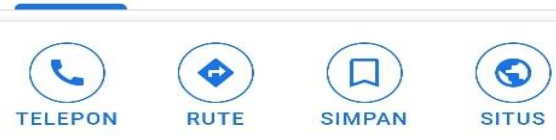

$\checkmark$ In-store shopping $\checkmark \checkmark$ Curbside pickup $\checkmark$ Delivery

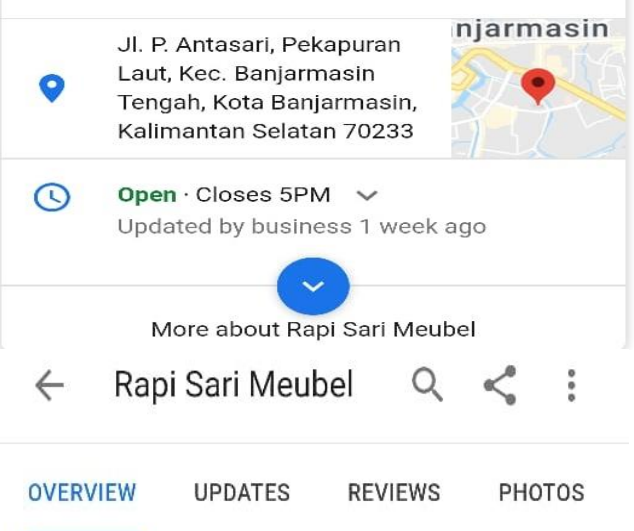

Questions \& answers
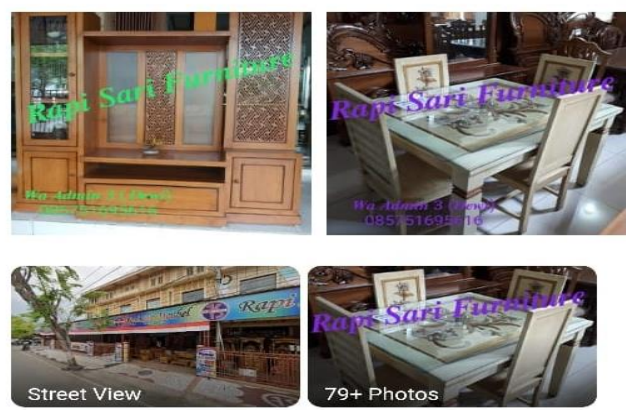

O Add a photo

Highlights

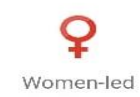

Ask the community

$\rightarrow$ See questions (2)

Review summary

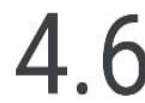

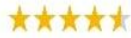

8 reviews

Gambar 10. Screenshot Tampilan Akun Google Bisnis Mitra UMKM

Adapun luaran dari kegiatan pengabdian kepada masyarakat "Penerapan Digital marketing Sebagai Strategi Pemasaran UMKM" berupa Artikel ilmiah dalam jurnal nasional "IMPACT" yang diterbitkan oleh Politeknik Negeri Banjarmasin edisi ke 2 tahun 2019 (dokumen submission terlampir) serta Laporan Kegiatan Pelaksanaan Kegiatan Pengabdian Kepada Masyarakat. 


\section{KESIMPULAN}

Hasil yang di capai melalui kegiatan Pengabdian Masyarakat dengan judul Penerapan Digital marketing Sebagai Strategi Pemasaran UMKM yang dilakukan oleh dosen Program Studi Administrasi Bisnis ini adalah sebagai berikut :

1. Di era sekarang ini, para pelaku UMKM hendaknya bisa memanfaatkan media digital sebagai salah satu upaya pemasaran produknya sehingga konsumen lebih mengenal produk yang dihasilkan oleh UMKM tersebut.

2. Perkembangan teknologi digital memungkinkan para pelaku UMKM untuk memasarkan produknya secara online dan melakukan transaksi melalui sistem perbankan secara online pula.

3. UMKM merupakan salah satu sektor usaha yang penting di Indonesia karena memiliki peranan yang penting bagi pertumbuhan ekonomi di Indonesia. Akan tetapi, masih banyak UMKM yang belum menerapkan teknologi informasi khususnya menggunakan media digital dan belum mengerti seberapa besar manfaat dan peranan penggunaan media digital tersebut.

4. Hasil yang didapat dari kegiatan pengabdian ini yaitu pemberian pelatihan mengenai pemanfaatan digital marketing sebagai sarana pemasaran produk usaha kepada Mitra Pengabdian. Kemudian dilanjutkan dengan pemberian tutorial pembuatan akun di media digital yang berpotensi untuk memperluas jangkauan pemasaran UMKM. Media digital yang digunakan di sini adalah Google Bisnis dan Media Sosial yaitu Instagram. Di sini, pelaku UMKM diberikan tutorial dan praktek membuat akun di ke dua media digital tersebut beserta cara mengoptimalkan ke dua media digital tersebut sebagai sarana promosi untuk jangkauan pemasaran yang lebih luas sehingga mampu mendorong penjualan produk yang lebih baik.

\section{SARAN}

Berdasarkan hasil yang diperoleh dalam kegiatan Pengabdian Masyarakat ini, maka saran untuk ke depannya yaitu sebaiknya penggunaan strategi digital marketing oleh Mitra Pengabdian dapat ditindaklanjuti dengan pembimbingan secara berkala sehingga bisa efektif dan optimal dalam menunjang kegiatan pemasaran usaha UMKM serta dapat meningkatkan penjualan usaha UMKM.

\section{DAFTAR PUSTAKA}

Ascharisa Mettasatya Afrilia. 2018. Digital Marketing Sebagai Strategi Komunikasi. Jurkom, Riset Komunikasi 1 (1). Hal 147-157.

Purwana ES, Dedi, Rahmi, Aditya, S. 2017. Pemanfaatan Digital marketing Bagi Usaha Mikro, Kecil, Dan Menengah (UMKM). Jurnal Pemberdayaan Masyarakat Madani (JPMM) 1(1). 1-17.

Purwana ESD, Rahmi, Aditya S. 2017. Pemanfaatan Digital marketing Bagi Usaha Mikro, Kecil, dan Menengah (UMKM) di Kelurahan Malaka Sari, Duren Sawit. JPMM. 1(1). doi : doi.org/10.21009/JPMM.001.1.01. 
Rachmawati, Fitri. 2018. Penerapan Digital marketing Sebagai Strategi Komunikasi Pemasaran Terpadu Produk Usaha Kecil Dan Menengah (UKM) Pahlawan Ekonomi Surabaya. Skripsi: Universitas Islam Negeri Sunan Ampel Surabaya Fakultas Dakwah Dan Komunikasi Jurusan Komunikasi Program Studi Ilmu Komunikasi. Surabaya.

Ridwan, Iwan Muhammad. Dkk. 2019. Penerapan Digital marketing Sebagai Peningkatan Pemasaran Pada UKM Warung Angkringan "WAGE" Bandung. JURNAL ABDIMAS BSI (Jurnal Pengabdian Kepada Masyarakat) Vol. 2 No. 1 Februari 2019, Hal. 137-142. E-ISSN : 26146711.

Wardana, Aditya. 2018. Strategi Digital marketing Dan Implikasinya Pada Keunggulan Bersaing UKM Di Indonesia. Prosiding Seminar Nasional: Forum Keuangan dan Bisnis IV, Th 2015. ISBN : 978-602-17225-4-1. 